\title{
Experimental Study on the Coaxing Effect of Multi-Level Stresses with Different Sequences
}

\author{
L. H. Zhao, ${ }^{\mathrm{a}, \mathrm{b}, 1}$ J. X. Li, ${ }^{\mathrm{a}}$ W. Y. Yu, ${ }^{\mathrm{a}}$ J. Ma, ${ }^{\mathrm{a}}$ and S. L. Zheng ${ }^{\mathrm{a}, \mathrm{b}}$ \\ ${ }^{a}$ School of Mechanical Engineering, University of Shanghai for Science and Technology, Shanghai, \\ China \\ ${ }^{\mathrm{b}}$ CMIF Key Lab for Automotive Strength and Reliability Evaluation, Shanghai, China \\ ${ }^{1}$ Pheigoe@126.com
}

The coaxing effect in fatigue refers to an increase in the fatigue strength of material imduced by prior cycling at a stress level below the fatigue limit. In this study, the coaxing effect of multi-level stresses in the fatigue process in the automotive drive shaft material $40 \mathrm{Cr}$ was investigated by applying three levels of stress amplitudes below the fatigue limit in different sequences prior to conducting the conventional constant amplitude fatigue test with standard round bar specimens. The existence of coaxing effect under multi-level stress with a load sequence effect was observed and confirmed by the results. The longest fatigue life is achieved through three levels of coaxing load with a step increase sequence, while a decrease sequence will result in the shortest fatigue life. The mechanisms of the coaxing effect which increased the fatigue life at the crack initiation and propagation stages were observed, through fracture morphology analysis, as the regulation of micropores, decreasing of pore density and the narrowed striation spacing. This finding is instrumental for extending the service life of mechanical components.

Keywords: coaxing effect, fatigue strength, load sequence effect, high-cycle fatigue.

Introduction. The coaxing effect in fatigue refers to an improvement of fatigue strength induced by prior cycling at a stress level below the fatigue limit. Early in the 1920 s, it was reported that the fatigue limit of mild steel was increased by $28 \%$ through step increasing the stress amplitude from $247 \mathrm{MPa}$ at an increment of $3 \mathrm{MPa}$ after every $10^{6}$ cycles [1]. Since then, much research has been conducted to study the coaxing effects in the fatigue of materials. Scott-Emuakpor et al. [2] found an improved fatigue performance that could be attributed to the coaxing effect during vibration-based bending fatigue loading using the step-test procedure when he studied fatigue lives of aerospace nickel alloys Inconel 625 and 718. Ishihara and McEvily [3] reported that the coaxing effect in the small crack growth regime can be achieved in S45C steel under a two-step loading with low-high sequence, due to a higher degree of crack closure inherited at high levels after transitions from lower levels than would be present under constant high amplitude conditions. Lu and Zheng $[4,5]$ studied coaxing effect of pre-understressing on carbon steels, and concluded that the stress amplitudes which will cause the coaxing effect range from 0.65 to 0.95 of the fatigue limit. Coaxing effect in fatigue of other materials have recently been reported, including aluminum alloys [6-8], metallic glass [9], fiber glass [10] and carbon composites $[11,12]$. Recent research has proposed other possible mechanisms for the coaxing effect including work hardening, strain aging, strain induced phase transformation, as well as strengthening at the tip of non-propagating cracks [13-15].

However, so far, the research into the coaxing effect has been performed under simple load conditions, such as pre-understressing [5-9], step incremental stress [3, 11] and two step repeated tests [4]. In practice, mechanical components are usually subject to variable amplitude loads with multi-level stresses and differing sequences. There is very little literature that relates to complex load conditions. For this paper, the integrated coaxing effect under a multi-level coaxing load of $40 \mathrm{Cr}$ was investigated by conducting conventional 
fatigue tests and coaxing effect tests on standard round bar specimens. Conventional fatigue tests were performed under constant amplitude above the fatigue limit. Coaxing effect tests were performed by applying three levels of load below the fatigue limit for certain cycles prior to the application of the constant amplitude load used in the conventional fatigue tests. The sequence effect in the coaxing effect was studied by applying three levels of load below the fatigue limit with three sequences. The coaxing effect based on fracture morphology and microstructure studies will also be discussed.

1. Coaxing Effect Test Setup. The tested material, $40 \mathrm{Cr}$, is a carbon steel consisting of $0.37-0.44 \mathrm{C}, 0.17-0.37 \mathrm{Si}, 0.5-0.8 \mathrm{Mn}, 0.8-1.1 \mathrm{Cr}, \leq 0.3 \mathrm{Ni}, \leq 0.035 \mathrm{P}, \leq 0.035 \mathrm{~S}$, and $\leq 0.03 \mathrm{Cu}$ (in wt.\%) with a yield strength of $785 \mathrm{MPa}$, ultimate tensile strength of $980 \mathrm{MPa}$, it is tempered at $520 \pm 10^{\circ} \mathrm{C}$ after being quenched at $850 \pm 10^{\circ} \mathrm{C}$. Fatigue tests and the coaxing effect tests were conducted under torsional conditions, on a Sagynomiya TT08 test machine utilizing a standard specimen, the shape and dimension of the test bed and specimen are shown in Fig. 1a. The stress ratio $R$ is set to 0.1 to avoid shock and vibration during testing. All specimens were tested at $30 \mathrm{~Hz}$ and room temperature. Prior to testing, the specimens were highly polished to diminish the influences brought out by surface roughness.
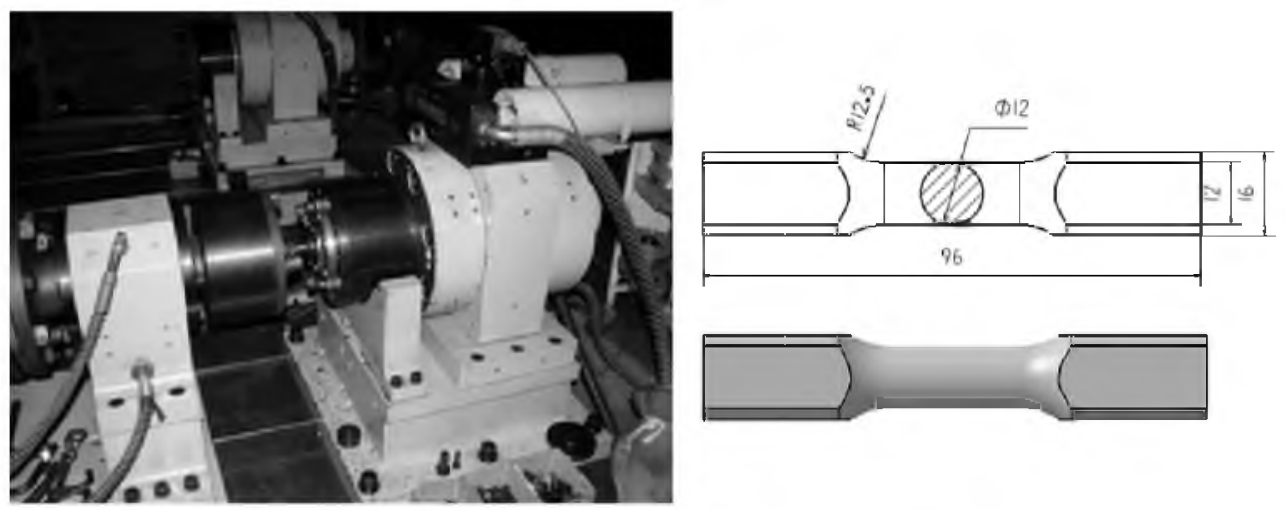

a

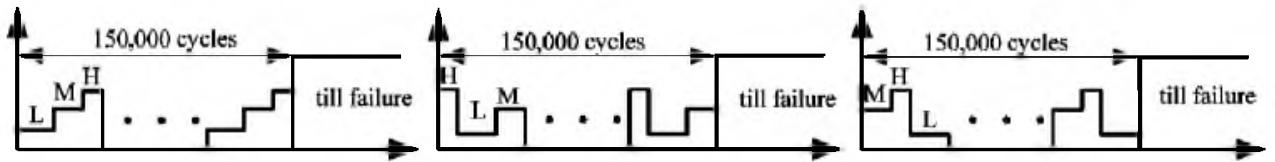

b

Fig. 1. Setup of the coaxing effect test: (a) test bed and specimen; (b) sequences of the three levels of load below the fatigue limit.

Fatigue tests under constant amplitude conditions were carried out to determine the $S-N$ curve and fatigue limit corresponding to a fatigue life at $2 \cdot 10^{6}$ cycles. Three stress levels, $0.75,0.85$, and 0.95 of the fatigue limit, were selected as the coaxing load for the coaxing test. The coaxing effect specimens were first subjected to a block loading of the three stress levels below the fatigue limit for 10 repetitions of 150,000 cycles, then fatigue tests were conducted under a stress level above the fatigue limit. In each repetition. three sequences were assessed and the number of cycles of each stress level was 5500, 3500 , and 1000 respectively. The three block loading and its construction are shown in Fig. 1b, the coaxing stress of the fatigue limit is represented by $L=0.75, M=0.85$, and $H=0.95$. 
2. Coaxing Effect Test Results. The results of conventional constant amplitude fatigue tests and coaxing effect tests are shown in Fig. 2. Seven specimens were tested under constant amplitude to determine finite life portion of $S-N$ curve. Two specimens were subjected to a maximum of $5 \cdot 10^{6}$ and $10^{7}$ cycles to ensure the fatigue limit. Coaxing effect was observed in the fatigue lives of the two groups of specimens. The fatigue life for the conventional constant amplitude fatigue test group ranged from 102,500 to 250,400 cycles with a mean value of 182,175 cycles across the six specimens. The fatigue life for the coaxing effect group ranged from 296,700 to 556,300 cycles with a mean value of 404,671 cycles across the seven specimens. The coaxing effect resulted in an average life more than double the constant test average life, and the minimum life in the coaxing group was longer than the maximum life in the constant test group. The results also indicate that sequence effect may exist in the coaxing effect, as the average lives of the coaxing group under sequences of $L-M-H, M-H-L$, and $H-L-M$ were $521,290,377,350$, and 345,140 cycles respectively. The coaxing effect is most significant when the coaxing load below the fatigue limit follows a step increasing sequence $L-M-H$.

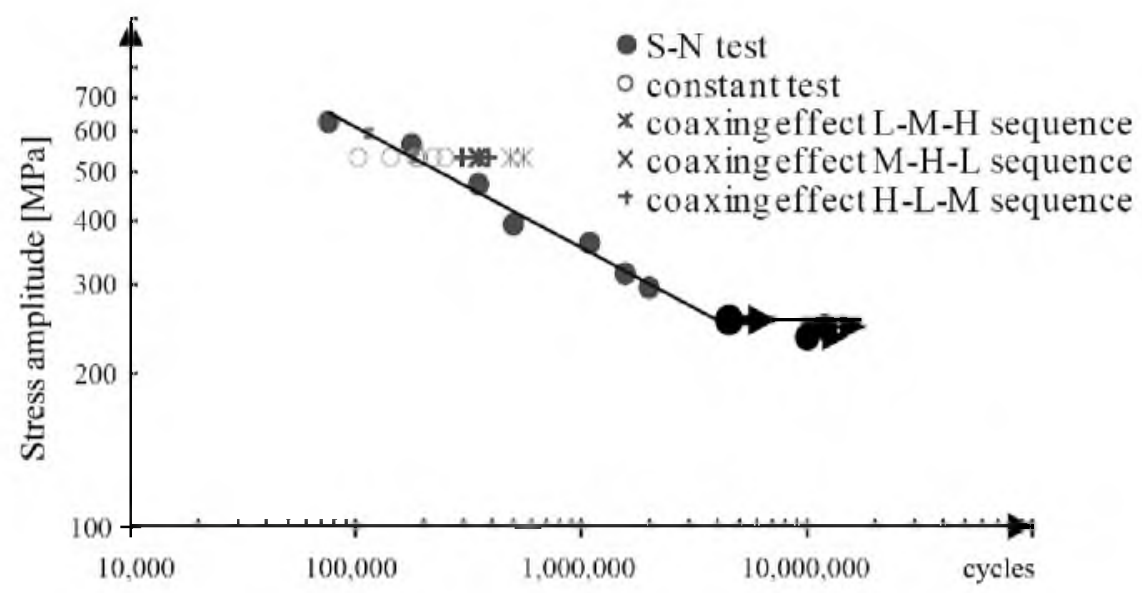

Fig. 2. $S-N$ curves with coaxing effect test results. (Arrows indicate that the specimens were not broken.)

3. Discussion. To confirm the coaxing effect, significance testing was carried out for the scatter of fatigue life. Hypotheses for the one-sided test were stated in terms of the mean value $\mu$ of the population as follows:

$$
H_{0}: \mu_{\text {constant }} \geq \mu_{\text {coaxed }} \quad \text { vs } \quad H_{a}: \mu_{\text {constant }}<\mu_{\text {coaxed }} \text { : }
$$

where $H_{0}$ corresponds to the case of no significant improvement in the fatigue life by coaxing, $H_{a}$ means the fatigue life was increased by coaxing effect on average, and $\mu_{\text {constant }}$ and $\mu_{\text {coaxed }}$ stand for the average life of the conventional constant amplitude fatigue test group and the coaxing group, respectively.

The $t$-test was adapted due to the two population variances being unknown and the specimen sizes not being equal. The statistic $t$ value is defined by Eq. (1):

$$
t=\frac{\overline{x_{1}}-\overline{x_{2}}}{S_{\overline{x_{1}}-\overline{x_{2}}}}=\frac{1}{\sqrt{\frac{1}{n_{1}}+\frac{1}{n_{2}}}} \frac{\overline{x_{1}}-\overline{x_{2}}}{\sqrt{\frac{\sum x_{1}^{2}-\left(\sum x_{1}\right)^{2} / n_{1}+\sum x_{2}^{2}-\left(\sum x_{2}\right)^{2} / n_{2}}{n_{1}-1+n_{2}-1}}}
$$


Taking 0.001 as the threshold value for statistical significance, the $p$-value at the $t$ value calculated according to Eq. (1) is 0.0002 , based on the fatigue lives of the two specimen groups. The null hypothesis $H_{0}$ is rejected in favor of the alternative hypothesis $H_{a}$, which verifies the coaxing effect.

Fracture morphology and microstructure studies on fatigue striation spacing, pore characteristics and secondary cracks were performed using scanning electron microscopy (SEM). Fatigue striation spacing was measured at the crack propagation region with a radial distance of $2.5 \mathrm{~mm}$ to crack initiation. Pores and secondary cracks are observed in the vicinity of crack initiation. Micrographs were taken from both specimen groups for comparison. Details of the micrographs taken using Leica S440i SEM are shown in Fig. 3.
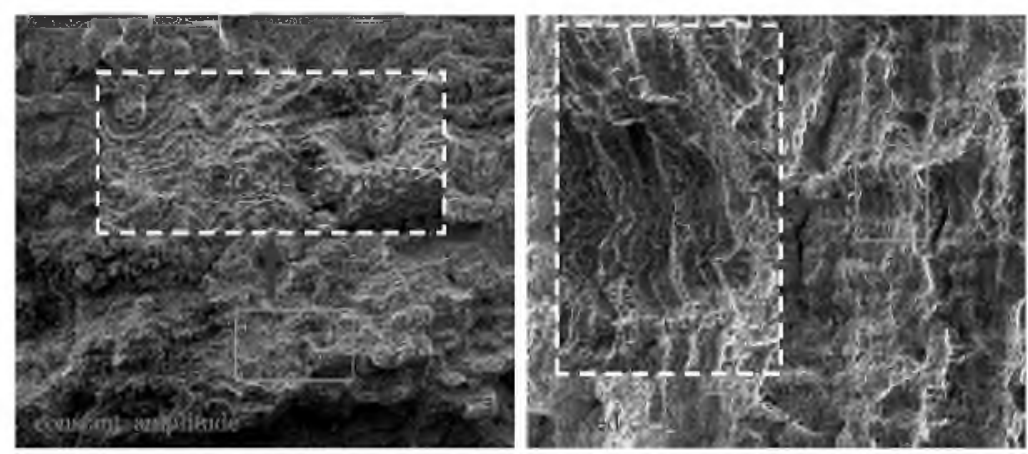

$200 \mu \mathrm{m}(\times 300)$

a
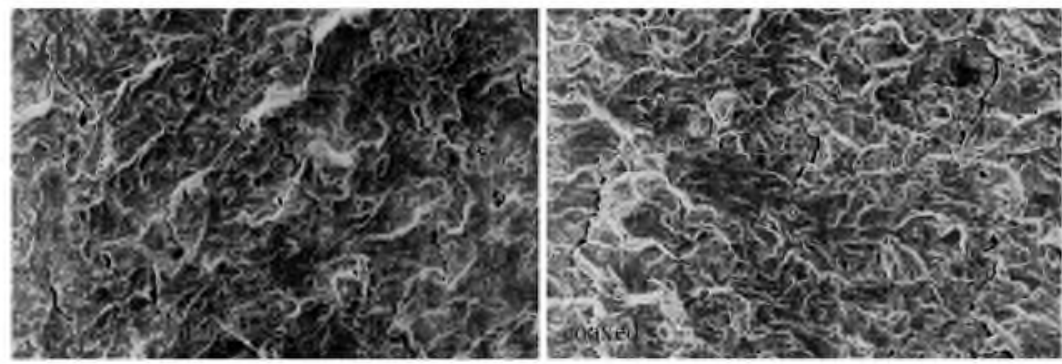

$-15 \mu \mathrm{m}(\times 1500)$

$\mathrm{b}$

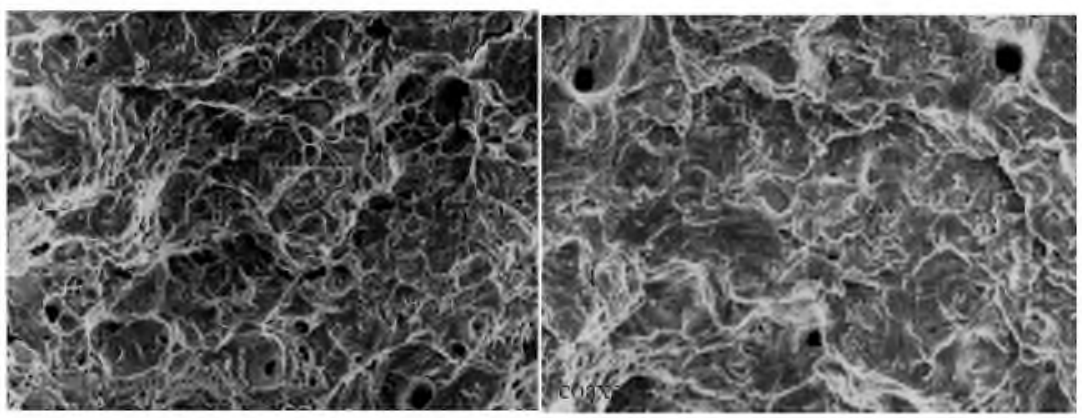

$10 \mu \min (\times 2000)$

$\mathrm{C}$

Fig. 3. Comparison of fracture surfaces of specimens under constant amplitude and coaxed under a sequence $L-M-H$ : (a) fatigue striation spacing; (b) secondary cracks; (c) characteristics of micropores. 
The striations of the fracture surface are shown in Fig. 3a. Seven striations at a distance of $52,051.5 \mathrm{~nm}$, with a mean spacing of $7.4 \mu \mathrm{m}$ were observed in the specimen from the constant test group. Eleven striations at a distance of $44,899.2 \mathrm{~nm}$, with a mean spacing of $4.1 \mu \mathrm{m}$ were observed in the specimen from the coaxed group, showing that the coaxing effect results in a reduction of the crack propagation rate evidenced by the narrowed striation spacing.

The secondary cracks on the section perpendicular to the main crack are depicted in Fig. $3 \mathrm{~b}$. It can be seen that the secondary cracks on the specimen under constant amplitude load were coarser and rougher than those on the specimen from the coaxing effect group. In accordance with pore densities, the density of secondary cracks on the specimen under constant amplitude is greater.

Several distinct pore characteristics differences were observed between the specimens, these are shown in Fig. 3c. The pore density is greater in the group under constant amplitude load than that of the coaxing effect group. The outlines of the pores after coaxing are smoother, and more circular. The observable pores were interconnected in the specimen under constant amplitude load, and independent in the specimen from the coaxing effect group. The improvement of the microstructure of the studied material caused by the coaxing effect leads to longer fatigue lives at the crack initiation stage.

Conclusions. In summary, the fatigue life of the material $40 \mathrm{Cr}$ can be prolonged through the coaxing effect of multi-level loads below the fatigue limit, this has been confirmed through fatigue tests and coaxing effect tests. This result is due to the improvement of the material microstructure, including the regulation of micropores and reduction of pore density, which eventually improves the fatigue strength. Additionally, load sequence effect appears to exist to some extent during the process of coaxing. The mean lives of the specimens after being coaxed by three levels of stress amplitudes below the fatigue limit with a sequence of $L-M-H, M-H-L$, and $H-L-M$ were $521,290,377,350$, and 345,140 cycles, respectively.

Though, statistically, the coaxing effect has been demonstrated by the t-test, according to the results of the fatigue test, the statistical nature of fatigue life cannot be ignored in the evaluation of load sequence effect. Since the specimen size is two in each situation, the variation of fatigue life of the coaxed specimens under different load sequences might simply be due to the differences in microstructure inherent in the material. More tests are needed in order to cover the scatter of fatigue life originating from the material inhomogeneous microstructure.

Acknowledgments. This work was supported by the National Natural Science Foundation of China (Grant No. 51375313).

\section{J. Schijve, Fatigue of Structures and Materials, Springer (2009).}

2. O. Scott-Emuakpor, J. Schwartz, T. George, et al., "In-situ study on coaxing during vibration-based bending fatigue of Inconel 625 and 718," in: ASME Turbo Expo 2013: Turbine Technical Conference and Exposition 2013 (June 3-7, 2013, San Antonio, TX), Paper No. GT2013-94233, ASME (2013), pp. V07AT27A003.

3. S. Ishihara and A. McEvily, "A coaxing effect in the small fatigue crack growth regime," Scripta Mater., 40, No. 5, 617-622 (1999).

4. X. Lu and S. L. Zheng, "Strengthening and damaging under low-amplitude loads below the fatigue limit," Int. J. Fatigue, 31, No. 2, 341-345 (2009).

5. X. Lu and S. L. Zheng, "Strengthening of transmission gear under low-amplitude loads," Mater. Sci. Eng. A, 488, No. 1, 55-63 (2008).

6. T. Shikama, Y. Takahashi, L. Zeng, et al., "Distinct fatigue crack propagation limit of new precipitation-hardened aluminium alloy," Scripta Mater., 67, No. 1, 49-52 (2012). 
7. Y. Takahashi, H. Yoshitake, R. Nakamichi, et al., "Fatigue limit investigation of 6061-T6 aluminum alloy in giga-cycle regime," Mater. Sci. Eng. A, 614, 243-249 (2014).

8. L. Zeng, Z. Li, R. Che, et al., "Mesoscopic analysis of fatigue strength property of a modified 2618 aluminum alloy," Int. J. Fatigue, 59, 215-223 (2014).

9. A. B. El-Shabasy and J. J. Lewandowski, "Fatigue coaxing experiments on a Zr-based bulk-metallic glass," Scripta Mater., 62, No. 7, 481-484 (2010).

10. M. Tomozawa, P. Lezzi, R. Hepburn, et al., "Surface stress relaxation and resulting residual stress in glass fibers: A new mechanical strengthening mechanism of glasses," J. Non-Cryst. Solids, 358, Nos. 18-19, 2650-2662 (2012).

11. Y. Tanabe, T. Yoshimura, T. Watanabe, et al., "Fatigue of $\mathrm{C} / \mathrm{C}$ composites in bending and in shear modes," Carbon, 42, Nos. 8-9, 1665-1670 (2004).

12. A. Ozturk, "The influence of cyclic fatigue damage on the fracture toughness of carbon-carbon composites," Compos. Part A-Appl. S., 27, No. 8, 641-646 (1996).

13. M. Akita, M. Nakajima, Y. Uematsu, et al., "Some factors exerting an influence on the coaxing effect of austenitic stainless steels," Fatigue Fract. Eng. M., 35, No. 12 , 1095-1104 (2012).

14. M. Nakajima, M, Akita, Y. Uematsu, and K. Tokaji, "Effect of strain-induced martensitic transformation on fatigue behavior of type 304 stainless steel," Proc. Eng., 2, No. 1, 323-330 (2010).

15. K. Kanazawa and M. Sugimoto, "Increasing behavior of strength for fatigue fracture of austenitic stainless steel during fatigue tests at elevated temperature," Key Eng. Mat., 417-418, 589-592 (2010). 